Revista de la red interuniversitaria de estudios sobre las literaturas rioplatenses contemporáneas en Francia

\title{
Los manuscritos de Borges: " Imaginar una realidad más compleja que la declarada al lector »
}

\section{Daniel Balderston}

\section{OpenEdition \\ Journals}

Edición electrónica

URL: http://journals.openedition.org/lirico/505

DOI: $10.4000 /$ lirico. 505

ISSN: 2262-8339

Editor

Réseau interuniversitaire d'étude des littératures contemporaines du Río de la Plata

\section{Referencia electrónica}

Daniel Balderston, «Los manuscritos de Borges: «Imaginar una realidad más compleja que la

declarada al lector » », Cuadernos LIRICO [En línea], 7 | 2012, Puesto en línea el 11 octubre 2012 consultado el 20 abril 2019. URL : http://journals.openedition.org/lirico/505 ; DOI : 10.4000/lirico.505

Este documento fue generado automáticamente el 20 abril 2019.

\section{(c) $(1) \odot \ominus$}

Cuadernos LIRICO está distribuido bajo una Licencia Creative Commons Atribución-NoComercialSinDerivar 4.0 Internacional. 


\title{
Los manuscritos de Borges: "Imaginar una realidad más compleja que la declarada al lector »
}

\author{
Daniel Balderston
}

1 Pierre Menard, el otro, el que no inventamos ni Borges ni Lafon ni yo, Menard el médico, escribe en su L'Ecriture et le subconscient: Psychanalyse et graphologie :

L'écriture est l'inscription graphique de gestes non surveillés dont on peut déterminer d'une façon précise et objective l'énergie, l'étendue, la direction, la forme, le rythme. Tous nos gestes traduisent nos états d'âme. La graphologie a donc una base solide, disons le mot, scientifique. ${ }^{1}$

No voy a intentar un psicoanálisis de Borges hoy según su escritura, aunque el Dr. Pierre Menard nos da en su libro, que se publicó en 1931, las herramientas para hacerlo. Pero sí recordar que Menard publicó un ensayo de análisis del Marqués de Sade en la revista Documents (dirigida por Georges Bataille) en diciembre de 1929, y un análisis del conde de Lautréamont en la revista Minotaure (dirigida por André Breton y Pierre Mabille), en mayo de 1939, el mismo mes de la publicación del texto de Borges en Sur. ${ }^{2}$ La preocupación que se expresa en el texto de Borges por la manera en que la escritura de un texto, la marca (o, como diría Borges después, la rúbrica) del autor, o lo que Menard llama los estados de ánimo del autor, es el tema de su libro, tan olvidado y -quizá- tan importante para la composición de"Pierre Menard, autor del Quijote."

La última nota del texto de Borges dice, de hecho:"Recuerdo sus cuadernos cuadriculados, sus negras tachaduras, sus peculiares símbolos tipográficos y su letra de insecto. En los atardeceres le gustaba salir a caminar por los arrabales de Nîmes ; solía llevar consigo un cuaderno y hacer una alegre fogata". ${ }^{3}$ La descripción es exacta para los manuscritos de Borges de la época. Los de"Pierre Menard","La biblioteca de Babel" y de"El jardín de senderos que se bifurcan" no están en papel cuadriculado sino en papel de contabilidad (marca Haber), con renglones verticales rosados para las columnas de debe y haber (como se puede apreciar en los catálogos de Lame Duck Books). Los de"La lotería en 
Babilonia" y"Las ruinas circulares" están en hojas no alineadas, con una letra chiquita y en renglones irregulares que van bajando hacia la derecha, con tachaduras negrísimas. ${ }^{4}$ Los de"El Aleph" sí están en papel cuadriculado, igual que los de"Abenjacán el Bojarí, muerto en su laberinto" (y el de"Kafka y sus precursores"). ${ }^{5}$ La letra es minúscula ("de insecto"), y en algunos casos las correcciones posteriores están marcadas con diversos símbolos geométricos ("peculiares símbolos tipográficos"), que se pueden apreciar, por ejemplo, en el manuscrito de un ensayo inédito sobre Martin Buber que está en la Fundación San Telmo y en el manuscrito de"Abenjacán el Bojarí".

4 En la tapa del manuscrito de"El Aleph" (el que le regaló a Estela Canto, que ella vendió por Sotheby's y que terminó en la Biblioteca Nacional de Madrid), escribe una estrofa del largo poema de Carlos Argentino Daneri :

He visto, como Ulises, las urbes de los hombres,

Los trabajos, los días de varia luz, el hambre ;

No he falseado los hechos, no he falseado los nombres,

Pues [Pero ?] el voyage que narro es autour de ma chambre.

Arriba del primer"he falseado" escribió"fingido" y abajo"formo + corrijo";"corrijo", la cuarta posibilidad ensayada, es la lectura definitiva en el poema. Arriba del segundo"he falseado" escribe"falseo", la palabra definitiva. La versión final de la estrofa, sin embargo, refleja algunos cambios que no se contemplan en la hoja manuscrita :

He visto, como el griego, las urbes de los hombres,

Los trabajos, los días de varia luz, el hambre ;

No corrijo los hechos, no falseo los nombres,

Pero el voyage que narro, es ... autor de ma chambre. (p. 618)

6 Por una anotación marginal en otra hoja del manuscrito de"El Aleph" nos enteramos que Carlos Argentino Daneri antes se llamaba"Uslanghi" (y hay otro apellido y fragmentos de descripción de él que no se pueden leer bajo la tachadura negra). También nos enteramos de que la lista de instantáneas de Beatriz Viterbo ("Beatriz, con su pekinés Wu-Li-Chang; Beatriz, sonriendo, la mano en el mentón, de frente y de tres cuartos" etc., en descripción ligeramente diferente de la definitiva, y con las instantáneas en otro orden) es un agregado : la primera descripción que prueba la absoluta frivolidad de la amada no forma parte de la versión inicial que Borges escribe en ese cuaderno de papel cuadriculado. (Hay otra versión de esa página, ya copiada en limpio, que incorpora ese agregado y el nombre definitivo del primo hermano). También nos podemos enterar de que en algún momento Borges pensó hacer que Beatriz Viterbo y Carlos Argentino fueran hermanos, no primos ${ }^{7}$; el hecho de que Estela Canto se jactara de haber tenido relaciones sexuales con su hermano (el filósofo Patricio Canto) ${ }^{8}$ habrá motivado esa asociación, aunque tal vez también fuera motivo para que se modificara.

7 En esos manuscritos de"El Aleph" de la Biblioteca Nacional de Madrid, que se han publicado en versión facsimilar en edición de Julio Ortega y Elena del Río Parra, hay algunas hojas que se han copiado en limpio, en las que las tachaduras se hacen de modo tan oscuras que no se puede leer lo que está por debajo de lo tachado (por lo menos en la versión facsimilar), y otras donde las muchas versiones se barajan en sucesión, con líneas que eliminan algunas de las posibilidades descartadas. Son interesantes algunas de las omisiones : Daneri, en el manuscrito,"[s]uele intercalar en el diálogo piezas de Alfonsina Storni, de Amado Nervo, de Juan Ramón Jiménez" (p. 53), preferencias que confirman, para"Borges" (el personaje) y seguramente también para Borges (el autor) el gusto dudoso de Daneri en materia de poesía. Donde Daneri dice en la versión publicada"¡Decididamente, tiene la palabra Goldoni!" el manuscrito 
dice :"¡Decididamente, Byron, y Musset tiene la palabra" (p. 56) ; Byron sobrevive hasta la versión del texto publicado en Sur en mayo de 1939, pero Musset perece antes, y los dos terminan sustituidos por Goldoni, el dramaturgo y libretista veneciano del siglo XVIII. Otro detalle fascinante : el narrador enumera las partes del mundo ya"despachad[as]" por Daneri en una lista que incluye en la versión publicada"unas hectáreas del estado de Queensland, más de un kilómetro del curso del ob, un gasómetro al norte de Veracruz, las principales casas de comercio de la parroquia de la Concepción, la quinta de Mariana Cambaceres de Alvear en la calle Once de Setiembre, en Belgrano, y un establecimiento de baños turcos no lejos del acreditado acuario de Brighton". Aquí el manuscrito incluye también, bajo tachadura, algunas zonas adicionales:"los cráteres del Etna, todas las cervecerías de Zürich" y, después del gasómetro veracruzano,"un túmulo en Canudos" (p. 57), claro indicio (confirmado en otras partes) de la lectura que hizo Borges en estos años de Os Sertões de Euclides da Cunha. Adicionalmente, hay referencias en el manuscrito a Hermes Trismegisto (p. 65) y a Farid al-Din Attar (p. 66) que no están en la versión final, donde es simplemente"un persa". El catálogo de las cosas que Borges ve en el Aleph incluye, en el manuscrito,"un ejemplar de la primera edición de Cherubinischer Wandersmann de Silesius" en una biblioteca de Córdoba (p. 67),"inacabables [o interminables] ojos inmediatos escrutándose en mí como en un espejo" (p. 67),"un poniente en Wind River" (p. 67),"convexos desiertos ecuatoriales y cada uno de sus granos de arena" (p. 67). Además, en el manuscrito"vi el Aleph" no es la culminación de la serie (p. 68), aunque las sucesivas referencias al Aleph en la tierra y la tierra en el Aleph y otra vez el Aleph, etcétera, sí. Otro tipo de enmienda: donde el texto publicado dice que"el crítico de gusto viril" sabrá apreciar el verso de Daneri sobre el lugar donde"se aburre una osamenta", Borges tacha esa frase, la sustituye por"hombre de gusto viril", y luego vuelve a la frase original. Daneri en el manuscrito dice"che Jorge", no"che Borges (p. 68). ${ }^{9}$

8 Lo que demuestra el estudio del manuscrito de"El Aleph" es que Borges escribe fundamentalmente por acumulación: traza un texto en la primera versión que es sustancialmente la definitiva, pero quita y agrega detalles. El cambio de orden de las instantáneas de Beatriz Viterbo, la larga pero incierta lista de cosas vistas en el Aleph, ${ }^{10}$ los detalles tachados y agregados, confirman ese proceso fundamental."El Aleph" es un manuscrito con numerosas tachaduras y correcciones (muchas más que los fragmentos publicados de los manuscritos de"La biblioteca de Babel","El jardín de senderos que se bifurcan","Funes" y Tlön"), pero eso puede ser también por la naturaleza acumulativa de ese relato. Cuatro o cinco visiones más, o menos, no alteran la estructura fundamental de la larga frase que comienza"Vi el populoso mar". Pero también es probable que el hecho de que ese cuento se escribiera para, y sobre, Estela Canto, cuando están en medio de una relación amorosa tormentosa, ${ }^{11}$ haya contribuido en este caso al hecho de que se hayan salvado versiones primitivas e intermedias, mientras la mayoría de los manuscritos que sobreviven de los cuentos de Ficciones y El Aleph parecen ser versiones copiadas en limpio.

9 Para el estudioso de Borges los manuscritos son en gran parte terra incognita. El manuscrito de"El Aleph" es el único accesible hasta ahora : está en la Biblioteca Nacional de Madrid, y la edición facsimilar se publicó por El Colegio de México. La Biblioteca Bodmer de Ginebra tiene manuscritos de"El Sur" y el recién adquirido manuscrito de"Tlön, Uqbar, Orbis Tertius" (el que, sin embargo, todavía figura en la página web de la librería Lame Duck Books en Cambridge, Massachusetts, a menos que sea otro manuscrito) pero que yo sepa nadie los ha trabajado todavía. Esa misma librería ha tenido a la venta en los últimos años manuscritos de"Funes el memorioso","El jardín de senderos 
que se bifurcan","La biblioteca de Babel","Pierre Menard, autor del Quijote" y otros muchos, pero esos manuscritos no están a la disposición del estudioso, a menos que tenga en el bolsillo casi medio millón de dólares (el precio promedio de cada uno): los manuscritos de"El jardín de senderos que se bifurcan" y"Pierre Menard" llevan precios de 450.000 dólares, según la página web de la librería (www.lameduckbooks.com), y el de"Tlön" $650.000 .{ }^{12} \mathrm{Y}$ hay casos mucho más molestos : tuve en mis manos por menos de una hora el manuscrito de"Hombre de la esquina rosada", pero la coleccionista no me dejó sacar fotocopias ni apuntes, y de modo patético no sabía que el principio del manuscrito del cuento incluía fragmentos de lo que serían"La postulación de la realidad" y"El arte narrativo y la magia", importantes ensayos de Discusión escrita en la misma época, como voy a comentar en un momento. Otros coleccionistas tendrán manuscritos pero no lo confiesan públicamente, sobre todo después del reciente escándalo cuando la viuda del escritor amenazó con ir al Japón para recuperar manuscritos que ella tildó de"robados" (pero los artículos que han salido en la prensa sobre el hecho han sido tan vagos que no permiten adivinar de qué manuscritos se trata). Estamos condenados, entonces, a sufrir, como deben sufrir los grandes violinistas al saber que muchos de los mejores instrumentos están en cajas fuertes en el sótano de algún banco, o en las vitrinas de algún museo, sin que puedan probar sus virtudes. Como dice el narrador de"Pierre Menard","la gloria es una incomprensión y quizá la peor" (p. 450) : en este caso el hecho de que Borges sea tan famoso y sus manuscritos tan escasos ha conspirado para que éstos hayan desaparecido de la circulación.

10 Me tendré que contentar por el momento, entonces, con la lectura de uno de los borradores más interesantes: la hoja que abre el cuaderno donde Borges escribió"Hombre de la esquina rosada". Esta hoja, la que pude consultar por la indulgencia breve de la dueña de ese importante manuscrito, se publica en forma facsimilar, con muy baja resolución, en el libro Borges: Develaciones de Félix della Paolera, en el inevitable año del centenario, 1999. La tapa del cuaderno lleva impresa el título Lanceros Argentinos de 1910, combinado de modo desconcertante con una cita de Luis XIV,"El camino más seguro de la gloria es el que la virtud señala". ${ }^{13}$ La letra de insecto de Borges cubre toda la página de modo caótico, en todas las direcciones, con superposiciones difíciles de leer. De los fragmentos que he logrado descifrar, varios tienen que ver con los ensayos"La postulación de la realidad" (1931) y"El arte narrativo y la magia" (1932), ambos incluidos en Discusión (1932). El hecho de que el mismo cuaderno (desgraciadamente deshecho y encuadernado de nuevo, así que es imposible saber qué otros borradores contuvo en algún momento) contenga el manuscrito de"Hombre de la esquina rosada", publicado inicialmente como"Hombres de las orillas" en la"Revista Multicolor de los Sábados" del diario Critica, en 1933, confirma su importancia. Se puede leer, por ejemplo, en la parte de arriba hacia la derecha,"la conducta clásica-ejemplos de Gibbon, de Cervantes, quizá (reductio ad absurdum) de Moratín, o del W. M. [Wilhelm Meisters Lehrjahre] de Goethe"."La postulación de la realidad" incluye la frase"Dicho con mejor precisión : no escribe los primeros contactos de la realidad, sino su elaboración final en concepto. Es el método clásico, el observado siempre por Voltaire, por Swift, por Cervantes" (p. 218). Aunque después desaparezcan Goethe y Moratín de la discusión, la idea desarrollada en el ensayo ya se vislumbra, aunque la hoja pasa sin solución de continuidad a anotaciones sobre"los sorprendentes defensores de Góngora", una mención de (¿Néstor?) Ibarra y de una monografía de Artigas, una referencia a Chuang Tzu, menciones del"serenísimo" Matthew Arnold, las traducciones inglesas de 
Homero,"algunas expresiones de Shakespeare" y la famosa frase de Alexander Pope"what oft was thought [but ne'er so well express'd]" (de"An Essay on Criticism").

11 Hay también fragmentos de The Life and Death of Jason (1867) de William Morris, y anota"sea... witches... breasts", ideas que surgen de la lectura de ese poema. Otro fragmento que se puede descifrar a medias dice :"se queda el ateniense que, ya ? ? de la tensión y largo el surco atrás de la nave atraviesa corre entre las dos filas de remeros, y se arroja desde la popa al mar -237 como diría - ¿dos mil quinientos años después o sólo cincuenta ?-alguna contaminación de Paul Valéry. -verificar-". En"El arte narrativo y la magia" podemos leer la versión final de esta idea, que dice (de nuevo a propósito del poema de Morris sobre Jasón, Medea y los argonautas) :

Prometen las sirenas un indolente cielo submarino, roofed over by the changeful sea (techado por el variable mar) según repetiría - ¿dos mil quinientos años después, o sólo cincuenta?- Paul Valéry. Cantan y alguna discernible contaminación de su peligrosa dulzura entra en el canto correctivo de Orfeo. Pasan los argonautas al fin, pero un alto ateniense, terminada ya la tensión y largo el surco atrás de la nave, atraviesa corriendo las filas de los remeros y se tira desde la popa al mar. (p. 229)

Es decir, en los pedazos de esta hoja que tienen que ver con"El arte narrativo y la magia", Borges esbozó una idea, citando pedazos del poema de Morris que recordaba, pero luego siguió sus propias instrucciones y verificó la cita, modificando la frase para acomodarla. Éste es el procedimiento que anota Bioy cuando dice en el diario, décadas después :

Borges insiste siempre en comprobar las citas. Me sale del alma la protesta y estoy a punto de pensar que entorpece el trabajo con una manía personal o capricho. Casi infaliblemente la enciclopedia le da la razón: la consulta no fue inútil, alguna corrección introduciremos en nuestro texto o en nuestros conocimientos. ${ }^{14}$ La anotación de Bioy llega a confirmar algo que se vislumbra aquí : que la memoria de la cita, y la anotación de algún fragmento recordado, antecede la búsqueda en el original y la ampliación del comentario.

Otro fragmento que tiene que ver con el poema de Morris :

la peligrosa música reconocida primero por Medea, su (previa) operación de felicidad en los rostros de los marineros que apenas tenían conciencia de oírla, la comunicación (sencilla y verosímil) de que al principio no se podían distinguir las palabras, dicha de modo indirecto : how sweet it was... Estas, una vez avistadas por los remeros, las sirenas, siempre... (cierta y alguna) distancia (for they were nigh enow..) y su poderío estético significado por [luego viene un triángulo, que parece remitir a otro triángulo arriba, donde continúa la frase] some dear delight y por las ansiosas lágrimas de los remeros, neblina (ansiosa) de lágrimas que sirven para no ? ? ? acercarlas demasiado también.

Esto se convierte en el ensayo de 1932 en :

Idéntica persuasión pero más gradual, la del episodio de las sirenas, en el libro catorce. Las imágenes preparatorias son de dulzura. La cortesía música reconocida primero por la hechicera Medea, su previa operación de felicidad en los rostros de los marineros que apenas tenían conciencia de oírla, el hecho verosímil de que al principio no se distinguían bien las palabras, dicho en modo indirecto :

And by their faces could the queen behold

How sweet it was, although no tale it told,

To those worn toilers o'er the bitter sea,

anteceden la aparición de esas divinidades. Éstas, aunque avistadas finalmente por los remeros, siempre están a alguna distancia, implícita en la frase circunstancial : 
for they were near enow

To see the gusty wind of evening blow

Long locks of hair across those bodies White

With golden spray hiding some dear delight.

El último pormenor : el rocío de oro - ¿de sus violentos rizos, del mar, de ambos o de cualquiera ?- ocultando alguna querida delicia, tiene otro fin, también : el de significar su atracción. Ese doble propósito se repite en una circunstancia siguiente: la neblina de lágrimas ansiosas, que ofusca la visión de los hombres. (p. 227-228)

Estamos ante una hoja de trabajo que incluye, entonces, fragmentos importantes de los dos ensayos de Borges más importantes en la elaboración de su teoría de la narrativa (y de su posterior práctica como narrador). Pero incluye además referencias a núcleos que tienen que ver con otros ensayos de la época como"Las versiones homéricas" (también de 1932). Y a la vez nos envía a una de las fuentes de la teoría de la narrativa esbozada por Borges en estos famosos ensayos, al libro William Morris de Alfred Noyes. En esta hoja, hay anotaciones que tienen que ver con las páginas 24 y 61 de este libro. En la 24 leemos:

The august simplicity of passages like that was now and always beyond the reach of Morris, as also was the marvellous resource of the rolling organ-music of Tennyson 's verse, exemplified in that sudden glorious change in the rhythmic beat where indeed one knows not the speech from the thought, the body from the soul of the poem, so perfectly are they wedded..$^{15}$ (Noyes 24 )

17 La anotación de Borges en la hoja dice simplemente :"ejemplo que (me) proporciona Tennyson y ver en el W. Morris de Noyes, 24 ", pero permite reconstruir la asociación de ideas que vincula la música del verso de Tennyson. En la página 61, en un pasaje que compara la presentación de la muerte del rey Arturo en Tennyson y en Morris, leemos en Noyes :

It is in more ways than one that the above may be opposed to the description in Tennyson of how an arm,"clothed in white samite, mystic, wonderful", arose from out the bosom of the lake, holding the sword. The last two lines, in which the wind and the bird are indicated as witnesses, is an admirable instance of Morris's method of indirect and subtle affirmation.

"Afirmación indirecta y sutil" : Borges desarrolla esta idea (bueno, la roba sin confesarla y luego la desarrolla) en un importante pasaje de"La postulación de la realidad", ya muy comentado por la crítica :

El segundo consiste en imaginar una realidad más compleja y referir sus derivaciones y efectos. No sé de mejor ilustración que la apertura del fragmento heroico de Tennyson, Mort d'Arthur, que reproduzco en desentonada prosa española, por el interés de su técnica. Vierto literalmente: Así, durante todo el día, retumbó el ruido bélico por las montañas junto al mar invernal, hasta que la tabla del rey Artús, hombre por hombre, había caido en Lyonness en torno de su señor, el rey Artús: entonces, porque su herida era profunda, el intrépido Sir Bediver lo alzó, Sir Bediver el último de sus caballeros, y lo condujo a una capilla cerca del campo, un presbiterio roto, con una cruz rota, que estaba en un oscuro brazo de terreno árido. De un lado yacía el Océano; del otro lado, un agua grande, y la luna era llena. Tres veces ha postulado esa narración una realidad más compleja: la primera, mediante el artificio gramatical del adverbio así; la segunda y mejor, mediante la manera incidental de trasmitir un hecho : porque su herida era profunda; la tercera, mediante la inesperada adición de $y$ la luna era llena. (p. 219-220)

19 Como Noyes venía comentando justamente el mismo pasaje en la página 24, y había puesto itálicas justamente en las frases"then, because his wound was deep" $y$ "On one side lay the Ocean, and on one/ Lay a great water, and the moon was full", podemos 
comprobar que las observaciones de Borges siguen de cerca las que había publicado Noyes veinticinco años antes, en 1908.

Es decir, una auténtica hoja de trabajo como esta del cuaderno"Lanceros Argentinos de 1910" permite reconstruir no sólo la futura prosa de Borges -son fragmentos todavía torpes de dos de sus ensayos más importantes- sino también reconstruir su lectura. Sin duda la filología que practica Noyes, y cuyo gran monumento es The Road to Xanadu de John Livingston Lowes (publicado justo antes, en 1927, y mencionado por Borges en"El sueño de Coleridge"), provee a Borges de algunos de sus ejemplos y sus técnicas importantes. A la vez, queda claro que ni Noyes ni Lowes son capaces de hacer el salto que se da en este cuaderno de observaciones sobre los poemas de Tennyson y Morris a la composición de"Hombre de la esquina rosada". Esta hoja manuscrita es una importante fuente para el estudio de los materiales prerredaccionales de Borges, y desgraciadamente una de las pocas a la que se tenga acceso, aunque no sea más que acceso a través de una imagen de baja resolución. Si tuviéramos más materiales de este tipo podríamos saber mucho más de cómo trabajaba Borges, tanto en la preparación de sus cuentos como de sus ensayos. Sin esos materiales, no nos queda más -como quiere el narrador de"Pierre Menard"- que tratar de leer, como en un palimpsesto, las huellas de la escritura"previa".

\section{BIBLIOGRAFÍA}

ANTELO, Raúl,"Poesía hermética y surrealismo". A Fonte (2000). http://www.geocities.com/ a_fonte_2000/antelo1.htm

BALDERSTON, Daniel, Out of Context: Historical Reference and the Representation of Reality in Borges, Durham: Duke UP, 1993.

BIOY CASARES, Adolfo, Borges, Buenos Aires : Destino, 2006.

BORGES, Jorge Luis, Obras completas. Buenos Aires : Emecé, 1974.

BORGES, Jorge Luis,"El Aleph" de Jorge Luis Borges : Edición crítica y facsimilar, comp. Julio Ortega y Elena del Río Parra, México : El Colegio de México, 2001.

BORGES, Jorge Luis, Deux fictions :"Tlön, Uqbar, Orbis Tertius" et"El Sur", édition, introduction et traduction de M. Lafon, Puf/Fondation Martin Bodmer, Coll. Sources, 2010, 268 p.

CANTO, Elena, Borges a contraluz, Buenos aires : Espasa Calpe, 1989.

DELLA PAOLERA, Félix, Borges : Develaciones. Buenos Aires : Fundación E. Costantini, 1999.

Jorge Luis Borges: A Catalogue of Unique Books and Manuscripts. Ed. Charles Vallely. Brookline, Massachusetts : Lame Duck Books, 2003.

LAFON Michel, Une vie de Pierre Ménard, París : Gallimard, 2009.

MENARD, Pierre, L'Ecriture et le subconscient : Psychanalyse et graphologie, París : Grasset, 1931. NOYES, Alfred, William Morris, Londres : Macmillan, 1908. Versión en línea en Google Books. 
PARODI, Cristina, reseña de"El Aleph" de Jorge Luis Borges : Edición crítica y facsimilar de Julio Ortega y Elena del Río Parra, Variaciones Borges 13 (2002). En línea en http://www.borges.pitt.edu/vb13/ ortega.php.

TORRE BORGES, Miguel de, comp., Borges : fotografías y manuscritos. Buenos Aires : Ediciones Renglón, 1987.

\section{NOTAS}

1. P. Ménard, L'Ecriture et le subconscient : Psychanalyse et graphologie, París : Grasset, 1931, p. 7.

2. Raúl Antelo ya advirtió la existencia de estas publicaciones del doctor Menard en las revistas surrealistas en"Poesía hermética y surrealismo". R. Antelo,"Poesía hermética y surrealismo". A Fonte (2000). http://www.geocities.com/a_fonte_2000/antelo1.htm.

3. J. L. Borges, Obras completas, Buenos Aires: Emecé, 1974, p. 450. Los números de página entre paréntesis remiten a esta edición.

4. Hay hojas facsimilares de los manuscritos de"Pierre Menard","La biblioteca","El jardín de senderos","La lotería en Babilonia" y"Las ruinas circulares" en los catálogos de Lame Duck Books. 5. Hay hojas facsimilares de los manuscritos de"Abenjacán" y"Kafka" en el libro que hizo el sobrino, Miguel de Torre Borges, Borges fotografías y manuscritos.

6. La versión definitiva se incorpora a otra versión ológrafa copiada en limpio.

7. J. L. Borges,"El Aleph" de Jorge Luis Borges : Edición crítica y facsimilar, comp. Julio Ortega y Elena del Río Parra, México : El Colegio de México, 200, p. 60. Los números de página entre paréntesis remiten a esta edición.

8. Este chisme me lo refirió Hugo Beccacece hace años. Según Beccacece, a los hermanos Canto les encantaba contar eso en las reuniones de Sur.

9. Sigo las lecturas del manuscrito que hacen Ortega y del Río Parra, a pesar de las advertencias que hace Cristina Parodi en una feroz reseña del volumen que apareció en Variaciones Borges.

10. En el manuscrito publicado en versión facsimilar, el orden final de las cosas vistas en el Aleph se indica con una serie de números ; la lista original es muy diferente.

11. Sobre esto, ver E. Canto, Borges a contraluz, Buenos Aires : Espasa Calpe, 1989.

12. El manuscrito de"Tlön" ha sido adquirido por la Biblioteca Bodmer de Ginebra, que ya tenía el manuscrito de"El Sur". Publicación posterior a la redacción del presente artículo : J. L. Borges, Deux fictions :"Tlön,Uqbar, Orbis Tertius" et"El Sur", édition, introduction et traduction de M. Lafon, Puf/Fondation Martin Bodmer, Coll. Sources, 2010, 268 p.

13. F. della Paolera, Borges : Develaciones, Buenos Aires : Fundación E. Costantini, 1999, p. 24.

14. A. Bioy Casares, Borges, Buenos Aires : Destino, 2006, p. 924.

15. A. Noyes, William Morris. Londres : Macmillan, 1908, p. 24. Versión en línea en Google Books.

\section{RESÚMENES}

El artículo propone un balance de las posibilidades de estudio de los manuscritos de Borges y describe algunos de ellos, en particular cuentos de Ficciones y El Aleph. En tanto que ejemplo, siguen algunos comentarios del manuscrito del cuento "El Aleph" y de una página de "Hombre de la esquina rosada" ; casos significativos porque permiten esbozar el interés de una investigación 
más amplia sobre el tema : a la vez los procedimientos de escritura de Borges, por acumulación, y las huellas dejadas en diferentes textos por sus lecturas, son así observables.

Cet article propose un bilan sur les possibilités d'étude des manuscrits de Borges, tout en décrivant certains, en particulier ceux des nouvelles de Ficciones et de El Aleph. En guise d'exemple, quelques commentaires sur le manuscrit de la nouvelle "El Aleph" et d'une page de "Hombre de la esquina rosada" sont avancés. Ce sont des cas significatifs car ils permettent d'ébaucher l'intérêt qu'aurait une recherche d'envergure sur le sujet; en effet, on peut ainsi observer à la fois le processus d'écriture de Borges (qui se faisait par accumulation) et les traces laissées par ses lectures dans des textes différents.

This article proposes a summary of the possibilities for studying Borges' manuscripts, while at the same time describing a number of them, in particular those of the short stories in Ficciones and El Aleph. By way of example, there follows commentary on the short story "El Aleph" and a page from "Hombre de la esquina roja". These two cases are significant in that they readily show the merit of a more ample investigation of the subject, for not only do we observe Borges' writing process (which is one of accumulation) but also the traces he left behind of his readings of various texts.

\section{ÍNDICE}

Mots-clés: Borges, "El Aleph", critique génétique, manuscrits

Keywords: "El Aleph", genetic criticism, manuscripts

Palabras claves: crítica genética, manuscritos

\section{AUTOR}

\section{DANIEL BALDERSTON}

University of Pittsburgh 